\title{
ADSORPTION AND KINETICS STUDIES OF Cu (II) IONS REMOVAL FROM AQUEOUS SOLUTION BY UNTREATED AND TREATED SUGARCANE BAGASSE
}

\author{
AKIODE O.K. ${ }^{1, *}$ \\ IDOWU M.A. ${ }^{2}$ \\ OMEIKE S.O. ${ }^{1}$ \\ AKINWUNMI F. ${ }^{1}$
}

\author{
${ }^{1}$ Institute For Human Resources Development (INHURD) \\ Federal University of Agriculture \\ PMB 2240, Abeokuta, Ogun state Nigeria \\ ${ }^{2}$ Department of Chemistry, Federal University of Agriculture \\ PMB 2240, Abeokuta, Ogun State, Nigeria
}

Received: $12 / 03 / 2015$

Accepted: 18/05/2015

*to whom all correspondence should be addressed:

Available online: 27/08/2015

e-mail: mubbil2010@gmail.com

\begin{abstract}
Adsorption of $\mathrm{CU}$ (II) ions by untreated sugarcane bagasse (USCB) and treated sugarcane bagasse (TSCB) was investigated. Sugarcane bagasse was treated with $0.1 \mathrm{M}$ oxalic acid prior to TSCB adsorption studies. Dependence of $\mathrm{Cu}$

(II) adsorption on

$\mathrm{pH}$, contact time, temperature and initial concentration of adsorbate solution were also investigated.

Optimum $\mathrm{pH} 2$ and contact time of 100

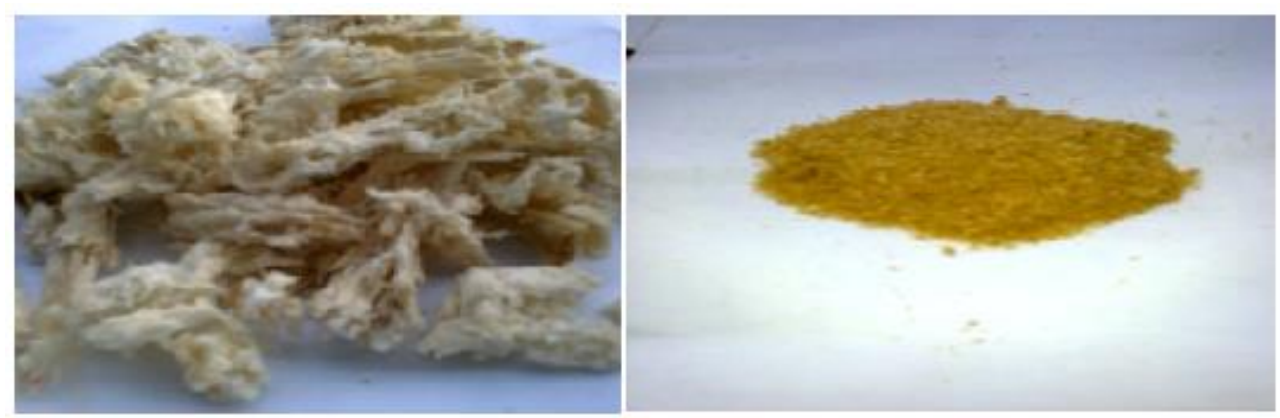

minutes were observed for both USCB and TSCB, while Cu II sorption increased with temperature. Under optimum condition, TSCB adsorbed CU (II) ions better than USCB (1.854 $\mathrm{mgg}^{-1}$ and $0.556 \mathrm{mgg}^{-1}$ respectively). Thermodynamic investigations showed that $\mathrm{Cu}$ (II) adsorption was feasible, spontaneous and endothermic. Kinetic data was adequately described by Ho's pseudo-second-order kinetic model while intra-particle diffusion model described a slow adsorption affinity. It was concluded that $\mathrm{Cu}$ (II) adsorption by sugarcane bagasse is a favourable chemisorption process and was well explained by both Langmuir and Freundlich isotherms.
\end{abstract}

Keywords: Copper(II), Sugarcane bagasse adsorbent, Isotherm models, Kinetics, Thermodynamics

\section{Introduction}

Toxic metals are a matter of concern to various forms of life and this makes it necessary for their removal, majorly from industrial and municipal wastewater. Accumulation of high intake of copper (over $1.0 \mathrm{mg} \mathrm{l}^{-1}$ in drinking water) in the liver of human beings and animals results to hemochromatosis and gastrointestinal problems (Pankaj Pandey et al., 2009). Copper is also toxic to aquatic organisms even at very low

Akiode O.K., Idowu M.A., Omeike S.O. and Akinwunmi F. (2015), Adsorption and kinetics studies of Cu(II) ions removal from aqueous solution by untreated and treated sugarcane bagasse, Global NEST Journal, 17(3), 583-593. 
concentration. The tolerable limits for $\mathrm{Cu}^{2+}$ in effluents released onto land according to Indian Standard Institute ISI specification is $3.0 \mathrm{mg} \mathrm{I}^{-1}$ (Archana et al., 2004); beyond this concentration, the effluents must be treated before disposal. Contamination of water and soil by industrial waste streams from metal cleaning, plating baths, mining, metallurgical, pulp and paper, fertilizers, wood preserving and excessive use of copper based agro-chemicals could release high load of copper into the environment where it is toxic and can act as a carcinogen (Meena et al., 2005).

A wide range of chemical methods are available for the removal of toxic metal ions from aqueous solutions. Recent chemisorptions approach has been carried out using the electrocoagulation technique. This technique has been used for the removal of toxic metals such as chromium, copper, manganese, nickel and zinc ions (Heidmann and Calmano, 2007; Bhatti et al., 2009; Vlachou et al., 2013; Gatsios et al., 2015). Other chemical methods include ion exchange, solvent extraction, reverse osmosis, precipitation, chemical oxidation and reduction, filtration, electrochemical treatment etc. However, these chemical methods are either inefficient or expensive, while some constitute more toxicity in the environment due to the generation of secondary wastes which could prove untreatable (Duygu et al., 2008; Ahamed and Begum, 2012).

The use of biological methods for removal of toxic metals from solution is encouraged over chemical methods, due to its economic advantage, availability of adsorbents and effectiveness. The widely accepted biological method of toxic metal clean up is adsorption. Adsorption is briefly explained as the retention and accumulation of metal ions unto the surface of solid materials in solution. A wide variety of adsorbents from different biological and agricultural sources such as sawdust, groundnut shell or fly ash, have been used for removal of copper ions from wastes and aqueous solutions (Teker et al., 1999; Shukla et al., 2005; Kaushir et al., 2007; Najua et al., 2008; Korrapati et al., 2009). Adsorbents have also been developed from organic and inorganic waste products including organic wastes of plants and animals with high carbon content (fruit waste, rice husks, bark, seaweed, algae, peat moss, hair and keratin) and inorganic materials such as mud soil, zeolites, ore materials and metal oxides with successful removal of toxic metals (Ali et al., 2012).

Sugarcane bagasse is a waste product from sugar refining industry. Bagasse is often considered as solid agrowaste material which is widely available and cause a significant disposal problem. Therefore, this cheap and unconventional biological material could be used as an adsorbent for the removal of ions of toxic metal from solution.

The use of both untreated and treated sugar cane bagasse as adsorbent for the removal of copper (II) ions from aqueous solutions was investigated and the adsorption process was explained using various models.

\section{Experimental procedure}

\subsection{Materials}

All chemicals used in the study were of analytical grade. Oxalic acid, Hydrochloric acid, Sodium hydroxide and anhydrous copper (II) sulphate were all purchased from Sigma-Aldrich. Stock solution (1000 $\left.\mathrm{mg} \mathrm{I}^{-1}\right)$ of adsorbate (CU (II) ions) was prepared by dissolving $2.51 \mathrm{~g}$ of dehydrated copper (II) sulphate in $1000 \mathrm{ml}$ deionized water in volumetric flask. Lower concentrations of adsorbate were prepared from stock solution by dilution. The biomaterial, sugarcane bagasse, was obtained from an indigenous sugar refinery.

\subsection{Equipment}

Pulverization of the bagasse was done using electric blender (Tamashi Model: TBG296-1), and the drying was in a hot-air oven (Uniscope SM9053). pH of solution was recorded using pH/ ion 510 meter (Eutech Instruments).Elemental analyses were carried out on an Atomic Adsorption Spectrophotometer, AAS (GBC model Analyst 400). 


\subsection{Preparation of adsorbent}

Sugar cane bagasse was pulverized and dried at $60^{\circ} \mathrm{C}$ for $12 \mathrm{~h}$ in a hot-air oven. Thereafter, it was sieved to uniform particle size of $100 \mu \mathrm{m}$ using a sieve of $100 \mu \mathrm{m}$ mesh size, kept in an air-tight container and labeled as untreated sugarcane bagasse (USCB). To prepare treated sugarcane bagasse (TSCB), USCB of uniform particle size $(100 \mu \mathrm{m})$ was treated with $0.1 \mathrm{M}$ oxalic acid for $48 \mathrm{hrs} \mathrm{in} \mathrm{a} \mathrm{conical} \mathrm{flask.} \mathrm{After} \mathrm{bleaching} \mathrm{with} \mathrm{oxalic}$ acid, treated bagasse was dried to constant mass and kept in an air-tight container for further studies.

\subsection{Batch Adsorption Experiments and Equilibrium Study}

Batch experiment has been carried out to find the optimum $\mathrm{pH}$, contact time, thermodynamic studies, equilibrium isotherms and kinetic studies.

Optimization of $\mathrm{pH}$ condition was carried out by adjusting the $\mathrm{pH}$ of adsorbate solution in the range 2.0-10.0. The $\mathrm{pH}$ adjustment of solution was done using $1.0 \mathrm{M} \mathrm{HCl}$ and $1.0 \mathrm{M} \mathrm{NaOH}$ and $\mathrm{pH}$ values confirmed using a $\mathrm{pH} /$ ion 510 meter (Eutech Instruments).Appropriate contact time was determined by allowing interaction of adsorbate to adsorbent between 20-120 minutes at 20-minute intervals. At each interval, residual $\mathrm{Cu}$ (II) concentration was analyzed. Effect of initial $\mathrm{Cu}$ II ion concentration was determined by preparing metal solution at different concentrations between $100-500 \mathrm{mg} / \mathrm{L}$. Thermodynamic effects were determined by carrying out sorption experiments at optimum conditions while varying temperature of the environment between $25-45^{\circ} \mathrm{C}(298-318 \mathrm{~K})$ at intervals of $5^{\circ} \mathrm{C}(5 \mathrm{~K})$.

Adsorption experiments were carried out by placing Erlenmeyer flasks on a Thermostat Orbital shaker, agitating the mixture at $150 \mathrm{rpm}$ at appropriate temperature for specified contact time of 100 mins and constant temperature. Equilibrium studies were carried out by varying initial $\mathrm{Cu}$ (II) concentration (25-100 mg l-1) with a working volume of $20 \mathrm{ml}$. Experiments were done in triplicates and average of data obtained was calculated. Control experiments were carried out by running adsorption of $\mathrm{Cu}$ (II) ions in appropriate concentrations in solutions without adsorbent. After contact period, the mixture was filtered using Whatmann's filter paper and residual concentration of $\mathrm{Cu}$ (II) ions in the filtrate $(5 \mathrm{~mL}$ ) was determined using the AAS.

Amount of metal ions adsorbed per gram of adsorbent and the efficiency of adsorption were calculated according to Equations 1 and 2 below:

$$
\begin{aligned}
& \qquad q_{e}=\frac{\left(C_{0}-C_{e}\right) V}{M} \\
& \text { Adsorption Efficiency }(\%)=\frac{\left(C_{0}-C_{e}\right) 100}{C_{o}}
\end{aligned}
$$

Where $\mathrm{q}_{\mathrm{e}}$ is amount of metal ions adsorbed per gram of adsorbent $\left(\mathrm{mg} \mathrm{g}^{-1}\right), \mathrm{C}_{\mathrm{o}}$ and $\mathrm{C}_{\mathrm{e}}$ is the initial and equilibrium concentration of the adsorbate $\left(\mathrm{mg} \mathrm{l}^{-1}\right)$ respectively, $\mathrm{V}$ is the volume of solution (I) and $\mathrm{M}$ is the mass of adsorbents (g).

\section{Results and discussion}

\subsection{Effect of $\mathrm{pH}$ on adsorption}

One of the most important factors which control the potential activity of an adsorbent in the uptake of toxic metals from aqueous solution- and consequently wastewater- is the acidity or alkalinity of the solution. The percentage removal of $\mathrm{Cu} I \mathrm{I}$ ions from solution by treated and untreated sugarcane bagasse was described in Fig. 1 and it can be deduced that $\mathrm{pH}$ of solution highly affected $\mathrm{Cu}$ II uptake. Highest $\mathrm{Cu}$ II uptake was observed for both TSSB and USCB at solution $\mathrm{pH}$ 2. However, TSCB showed higher adsorption rate of $73.8 \%$ than USCB which removed $\mathrm{Cu}$ II at a rate of $52.22 \%$ over the same contact period. However, there was continuous 
decrease in adsorption capacity for both USCB and TSCB with increase in pH of metal solution. A steady decrease in adsorption capacity was observed for USCB while over 59\% of copper ions were removed from solution up to weak acidic $\mathrm{pH} 6$ by TSCB. It was also observed that there was rapid decrease in adsorption rate thereof for TSCB while both adsorbent types showed similar adsorption rate in alkaline $\mathrm{pH}$ range. Optimum pH observed and continuous decrease beyond optimum pH could be due to the effect of a net positive charge on the surface of sugar cane bagasse in untreated and treated state at low pH optimum of 2. This indicates strong electrostatic force for attraction between $\mathrm{CU}$ (II) ion and the adsorbents as a result of anions formed from net positive charge on the surface of adsorbents.

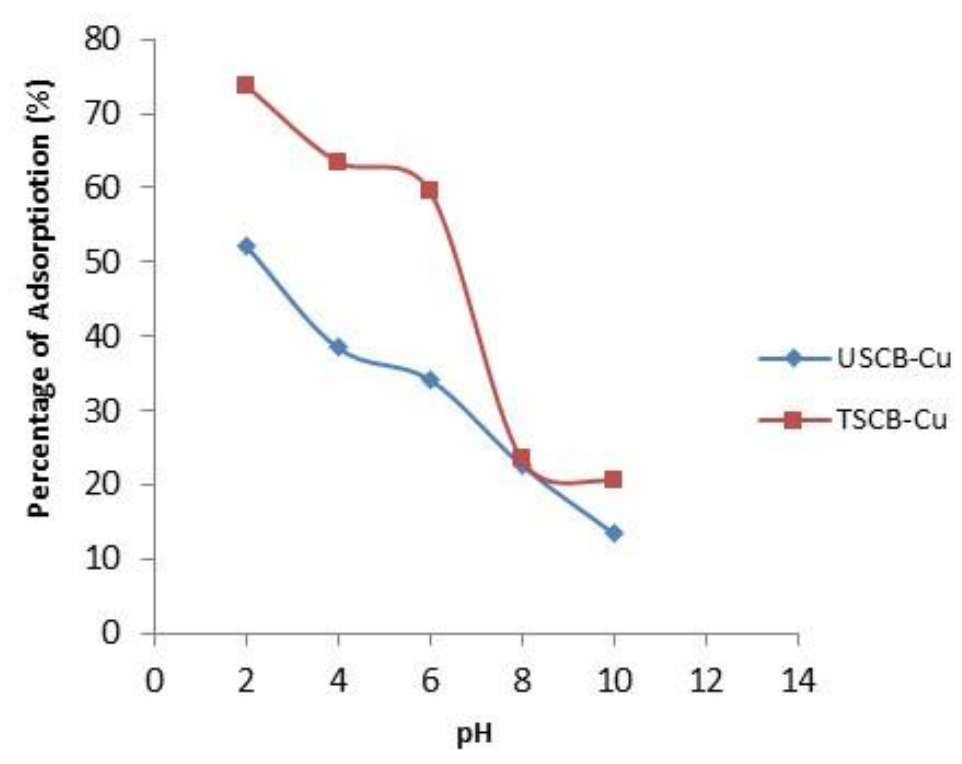

Figure 1: Effect of $\mathrm{pH}$ on adsorption of Copper (II) ions. Initial $\mathrm{Cu}$ (II) ions conc. $=100 \mathrm{mg} \mathrm{l}^{-1}$, Adsorbent dosage $=0.2 \mathrm{~g} / 20 \mathrm{ml}$, Contact time $=100 \mathrm{~min}$., Agitation speed $=150 \mathrm{rpm}$.

\subsection{Effect of contact time}

The effects of exposure period on the adsorption rate of Cu II by USCB and TSCB were illustrated in Fig. 2.

Optimum sorption time was observed at $100 \mathrm{mins}$ for both treated and untreated adsorbent. It was observed that there was increase in adsorption rate with increased contact between both types of adsorbent and the metal solution. Copper II ions removal increased from $35.68 \%$ and $45.28 \%$ after 10 mins of exposure to $68.63 \%$ and $84.58 \%$ removal rate at 100 mins for USCB and TSCB respectively. No further increase in adsorption rate was observed for both adsorbents beyond $100 \mathrm{mins}$. Also, more than $60 \%$ was removed after $20 \mathrm{mins}$ contact between $\mathrm{Cu}$ II ions and TSCB, result similar to the maximum sorption rate achievable by USCB.

Optimum sorption period for maximum Cu II ions sorption is comparable with reports of Julkapli et al., 2013 using chitosan-gel adsorbents for Cu II removal and Kareem et al., (2014) for use of fungi as biosorbent for toxic metals' uptake from solution.

Adsorption of over $60 \%$ in 20 mins by TSCB compared to $40 \%$ by USCB over the same period indicates the presence and availability of active binding sites at the initial sorption process with more binding activity occurring in TSCB.

Continuous sorption activity beyond 100 mins optimum contact period yielding no further increase in adsorption rate could be attributed to exhaustion of binding sites (Qaiser et al., 2009). 


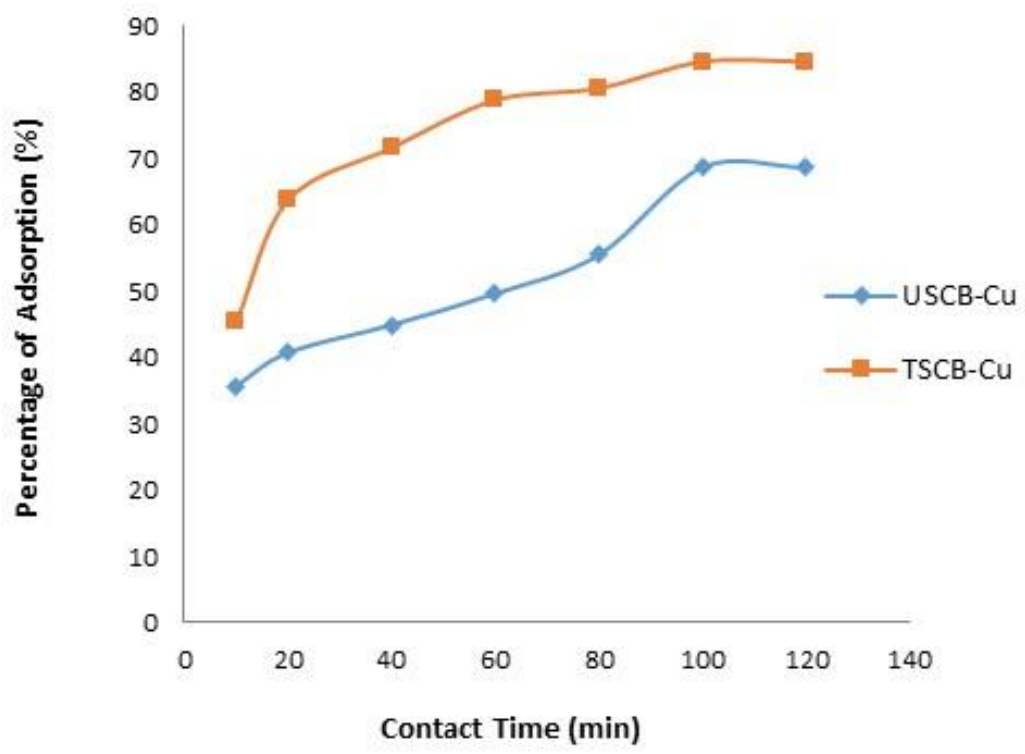

Figure 2: Effect of contact time on adsorption of Copper (II) ions.

Initial $\mathrm{Cu}$ (II) ions conc. $=100 \mathrm{mg} \mathrm{I}^{-1}$, Adsorbent dosage $=0.2 \mathrm{~g} / 20 \mathrm{~mL}, \mathrm{pH} 2$, Agitation speed $=150 \mathrm{rpm}$

\subsection{Effect of initial concentration of $\mathrm{Cu}$ (II) ions}

Efficiency of adsorption of $\mathrm{CU}$ (II) ions at various initial concentrations of $\mathrm{Cu}$ (II) ions described in Figure 3 showed that TSCB showed higher adsorption rate of $84.58 \%$ than USCB with $68.63 \%$ at an optimum initial metal concentration of $100 \mathrm{mg} / \mathrm{L}$. this implies that there was decrease in adsorption rate with increase in adsorbate concentration. However, over $50 \%$ removal rate was maintained by both types of adsorbent for the metal concentration range studied.

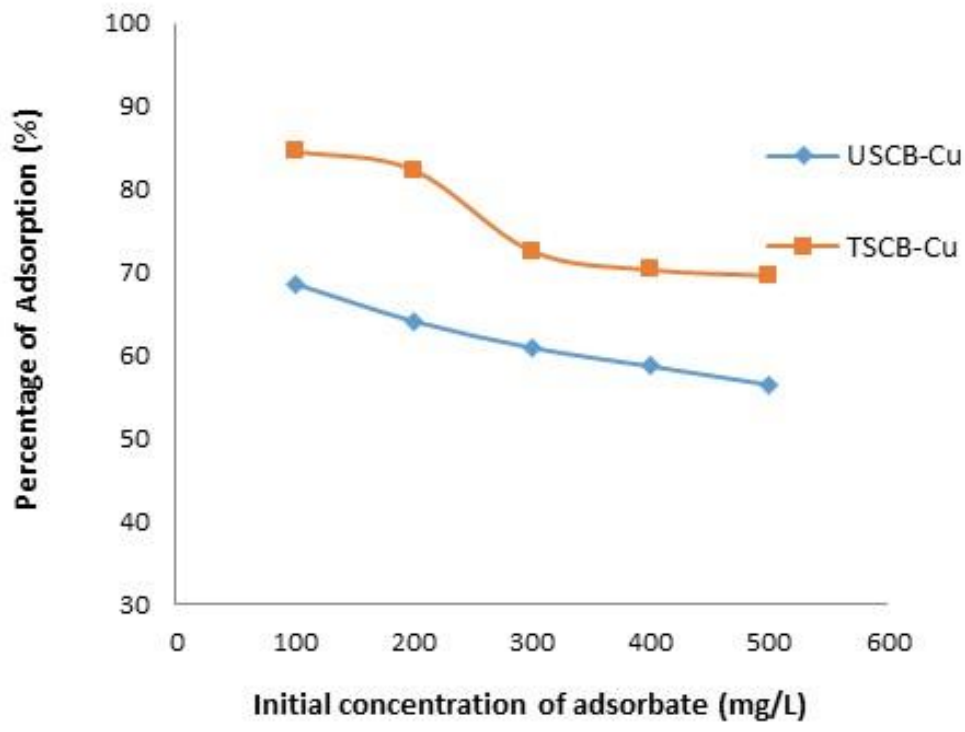

Figure 3: Effect of initial concentration on adsorption of Copper (II) ions. Adsorbent dosage $=0.2 \mathrm{~g} / 20 \mathrm{~mL}$, $\mathrm{pH} 2$, Contact time $=100 \mathrm{~min}$. , Agitation speed $=150 \mathrm{rpm}$. 
This is as a result of bulk mass transfer of $\mathrm{Cu}$ (II) ions at the surface of the adsorbents. After the saturation of the $\mathrm{Cu}$ (II) ions on the surface of the adsorbents more $\mathrm{Cu}$ (II) ions in excess surrounding the adsorbents causes desorption of the excess adsorbate. Also, higher adsorption rate at higher concentrations by TSCB compared to USCB indicates the availability of more activity sites on adsorbent surface although this was not enough to react more $\mathrm{Cu}$ II ions due to the larger number of the ions at higher concentrations (Khalid et al., 2000).

\subsection{Equilibrium Adsorption Isotherm Models}

In this research work, Langmuir (Langmuir, 1918) and Freundlich isotherm (Freundlich and Hatfield, 1926) models were used to analyze adsorption data by fitting them into the models. The linear forms of these equations are expressed in equation (3) and (5) below respectively.

$$
\frac{1}{q_{e}}=\frac{1}{q_{m} b C_{e}}+\frac{1}{q_{m}}
$$

Where, $\mathrm{q}_{\mathrm{e}}$ is the amount of adsorbate adsorbed per unit amount of adsorbent $\left(\mathrm{mgg}^{-1}\right), \mathrm{C}_{\mathrm{e}}$ the equilibrium concentration $\left(\mathrm{mgl}^{-1}\right), \mathrm{b}$ Langmuir equilibrium or adsorption constant $\left(\mathrm{mg}^{-1}\right)$ and $\mathrm{q}_{\mathrm{m}}$ Langmuir monolayer saturation capacity $\left(\mathrm{mgg}^{-1}\right)$.

Essential feature of the Langmuir isotherm can be expressed by means of $R_{L}$, a dimensionless constant referred to as a separation factor or equilibrium parameter. $R_{L}$ is calculated by

$$
\mathrm{R}_{\mathrm{L}}=\frac{1}{1+\mathrm{bC}}
$$

Where, $\mathrm{C}_{\mathrm{o}}$ is the initial concentration of $\mathrm{Cu}(\mathrm{II})$ ions $\left(\mathrm{mg} \mathrm{l}^{-1}\right)$ and $\mathrm{b}$ is obtained from slope of Langmuir plot. Favourable copper adsorption is confirmed by the value of $R_{L}$ in the range 0 to 1 .

The Freundlich linearized equation can be described by

$$
\log q_{e}=\log k_{f}+\frac{1}{n} \log C_{e}
$$

Where, $\mathrm{k}_{\mathrm{f}}$ is constant that described the adsorption capacity of the adsorbent $\left(\mathrm{mg} \mathrm{g}^{-1}\right)$, $\mathrm{n}$ is empirical parameter that dictates the intensity of the adsorption. The value of $\mathrm{k}_{\mathrm{f}}$ and $\mathrm{n}$ are determined by intercept and slope of the plot of $\log \mathrm{q}_{\mathrm{e}}$ against $\log \mathrm{C}_{\mathrm{e}}$ respectively.

The favourable uptake of $\mathrm{Cu}$ (II) ions confirm by the value of $\mathrm{R}_{\mathrm{L}}$ in the range of 0 to 1 at all initial $\mathrm{Cu}$ (II) ions concentration shown in Table 1.

Isotherm constants for adsorption of Cu II by USCB and TSCB are described in Table 1. Adsorption data by both adsorbents fitted into the adsorption models, indicated by $\mathrm{R}^{2}$ values higher than 0.9 . Dimensionless constant for both adsorbents was between 0-1, describing a favorable sorption process. Langmuir constant, $b$, was higher in TSCB than when USCB was used for Cu adsorption. This shows that TSCB has higher affinity to react with $\mathrm{Cu}$ ions in solution than USCB. Empirical parameter, $n$, determined from the slope was higher than 1 for both adsorbent types and this indicates a homogenous adsorbent surface. Higher $n$ value for $\mathrm{Cu}$ adsorption using TSCB describes a more favourable $\mathrm{Cu}$ II adsorption in comparison with USCB (Haghseresht and Lu, 1998; Adamson, 2001; Fytianos et al., 2003).

Table 1: Adsorption isotherms data for adsorption of $\mathrm{Cu}$ (II) ions

\begin{tabular}{cccccccc}
\hline & \multicolumn{3}{c}{ Langmuir parameters } & \multicolumn{3}{c}{ Freundlich parameters } \\
Adsorbents & $\mathrm{q}_{\mathrm{m}}\left(\mathrm{mg} \mathrm{g}^{-1}\right)$ & $\mathrm{B}\left(\mathrm{I} \mathrm{mg}^{-1}\right)$ & $\mathrm{R}_{\mathrm{L}}$ & $\mathrm{R}^{2}$ & $\mathrm{n}$ & $\mathrm{K}_{\mathrm{f}}\left(\mathrm{mg} \mathrm{g}^{-1}\right)$ & $\mathrm{R}^{2}$ \\
\hline USCB & 55.56 & 0.0045 & 0.69 & 0.996 & 1.366 & 0.556 & 0.999 \\
TSCB & 43.48 & 0.0159 & 0.39 & 0.988 & 1.739 & 1.854 & 0.975 \\
\hline
\end{tabular}




\subsection{Thermodynamic studies}

Temperature effects on $\mathrm{CU}$ II adsorption by USCB and TSCB were described in Figure 4 . It showed that adsorption of $\mathrm{Cu}$ by both adsorbents increased with increasing temperature of the reaction environment. Temperature had a higher effect on USCB, increasing $\mathrm{Cu}$ adsorption from 60 to $80 \%$, while TSCB maintained an $80 \%$ adsorption rate at all temperatures investigated. These observations imply that the adsorption process is endothermic in nature with external heat needed to improve adsorbate-adsorbent interactions.

Thermodynamic parameters such as free energy change $(\Delta G)$, enthalpy change $(\Delta H)$ and entropy change $(\Delta S)$ were determined using equations 6-8 and values are summarized in Table 2.

$$
\begin{aligned}
& \Delta \mathrm{G}=-\mathrm{RTInK} \mathrm{K}_{\mathrm{c}} \\
& \mathrm{K}_{\mathrm{c}}=\mathrm{q}_{\mathrm{e}} / \mathrm{C}_{\mathrm{e}}
\end{aligned}
$$

$\Delta \mathrm{G}=\Delta \mathrm{H}-\mathrm{T} \Delta \mathrm{S}$

Where, $\Delta G^{0}$ is standard free energy change (Joules), $R$ is universal gas constant $\left(8.314 \mathrm{Jmol}^{-1} \mathrm{~K}^{-1}\right), T(K)$ is the absolute temperature, $K_{\mathrm{c}}$ is the adsorption equilibrium, $q_{e}$ is the adsorption capacity of adsorbent at equilibrium and $C_{\mathrm{e}}$ is the residual concentration of adsorbate.

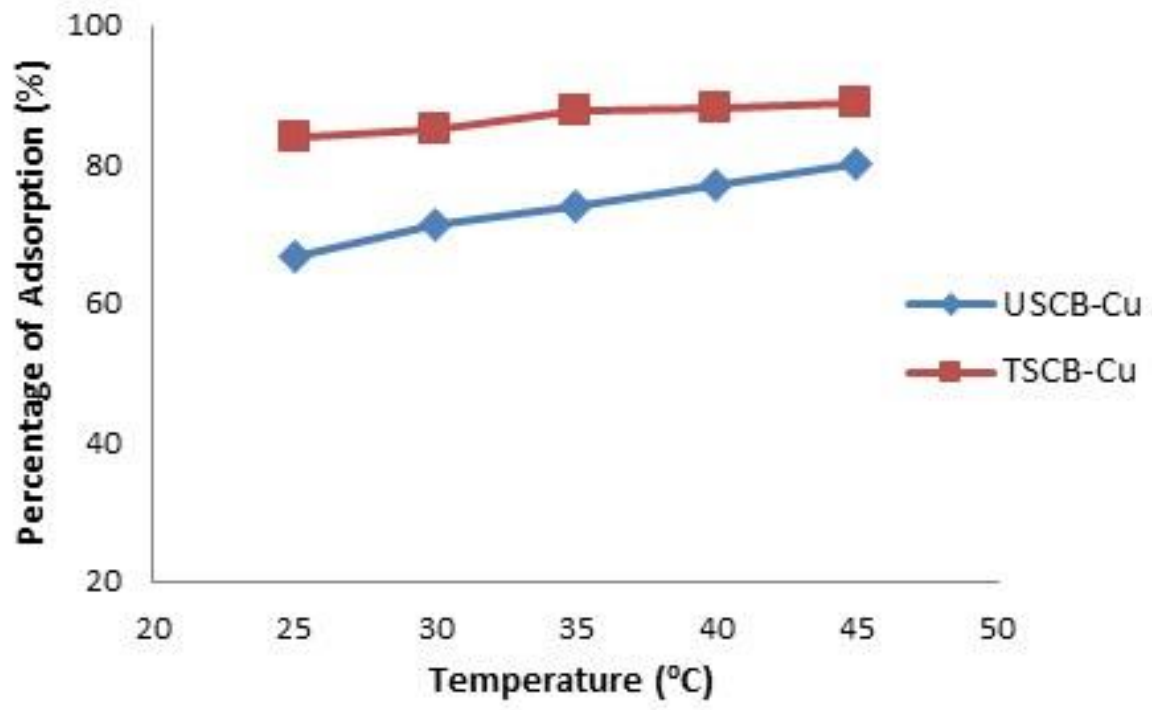

Figure 4: Effect of Temperature on adsorption of copper (II) ions. Initial Cu (II) ions conc. = $100 \mathrm{mg} \mathrm{l}^{-1}$, Adsorbent dosage $=0.2 \mathrm{~g} / 20 \mathrm{~mL}, \mathrm{pH} 2$, Contact time $=100 \mathrm{~min}$., Agitation speed $=150 \mathrm{rpm}$.

Table 2: Thermodynamic parameters for $\mathrm{Cu}$ (II) ions adsorption onto untreated and treated sugarcane

\begin{tabular}{|c|c|c|c|c|c|c|c|c|}
\hline \multirow[b]{2}{*}{$\begin{array}{l}\text { Temperature } \\
\text { (K) }\end{array}$} & \multicolumn{3}{|c|}{ USCB } & \multirow[b]{2}{*}{$\mathrm{R}^{2}$} & \multicolumn{4}{|c|}{ TSCB } \\
\hline & $\Delta \mathrm{G}(\mathrm{kJ} / \mathrm{mol})$ & $\begin{array}{c}\Delta \mathrm{S} \\
(\mathrm{kJ} / \mathrm{k} / \mathrm{mol})\end{array}$ & $\begin{array}{c}\Delta \mathrm{H} \\
(\mathrm{kJ} / \mathrm{mol})\end{array}$ & & $\Delta \mathrm{G}(\mathrm{kJmol})$ & $\begin{array}{c}\Delta \mathrm{S} \\
(\mathrm{kJ} / \mathrm{k} / \mathrm{mol})\end{array}$ & $\begin{array}{c}\Delta \mathrm{H} \\
(\mathrm{kJ} / \mathrm{mol})\end{array}$ & $R^{2}$ \\
\hline 298 & -1.729 & \multirow{5}{*}{0.094} & \multirow{5}{*}{26.42} & \multirow{5}{*}{0.995} & -4.122 & \multirow{5}{*}{0.072} & \multirow{5}{*}{17.45} & \multirow{5}{*}{0.953} \\
\hline 303 & -2.323 & & & & -4.376 & & & \\
\hline 308 & -2.68 & & & & -5.071 & & & \\
\hline 313 & -3.157 & & & & -5.173 & & & \\
\hline 318 & -3.677 & & & & -5.534 & & & \\
\hline
\end{tabular}
bagasse. 
Negative free energy change $(\Delta G)$ values obtained confirm the feasibility and spontaneity of the adsorption process. Also, positive enthalpy and entropy changes were described for both USCB and TSCB were described changes for both adsorbents (Table 2 ) and this confirms an endothermic sorption process. Enthalpy value of USCB $\left(26.42 \mathrm{kJmol}^{-1}\right)$ was higher than that of TSCB $\left(17.45 \mathrm{~kJ} \mathrm{~mol}^{-1}\right)$, indicating that higher temperature would be required to achieve high $\mathrm{Cu}$ Il sorption comparable with TSCB sorption.

Similarly, positive entropy change indicates an endothermic process with a high degree of randomness. There is a higher degree of randomness using USCB $\left(0.094 \mathrm{kJk}^{-1} \mathrm{~mol}^{-1}\right)$ than when TSCB $\left(0.072 \mathrm{kJk}^{-1} \mathrm{~mol}^{-1}\right)$ is used in Cu II removal from aqueous solution.

\subsection{Kinetic studies}

The rate constant of adsorption $\mathrm{CU}$ (II) adsorption by USCB and TSCB were determined from the pseudo firstorder equation (Equation 9; Langergren and Svenska, 1998) and the second-order equation (Ho and McKay, 1998; Equation 10) respectively. The mechanism of adsorption process by mass transfer was analyzed by intra-particle model described in equation 11.

$$
\begin{aligned}
& \log \left(q_{e}-q_{t}\right)=\log q_{e}-\frac{k_{1} t}{2.303} \\
& t / q_{t}=\frac{1}{k_{2} q_{e}^{2}}+\frac{1}{q_{e} t} \\
& q_{e}=k_{w} t^{0.5}
\end{aligned}
$$

Where $k_{w}$ is intra particle diffusion rate constant $\left(\mathrm{mgg}^{-1} \mathrm{~min}^{0.5}\right), q_{\mathrm{t}}$ is amount of adsorbate adsorbed on adsorbent at contact time $\mathrm{t}(\mathrm{min}), k_{1}$ and $k_{2}$ are equilibrium rate constant of pseudo-first- and second-order adsorption $\left(\mathrm{min}^{-1}\right)$.

All the data obtained from these studies were expressed in Table 3. Using the pseudo-first order equation, the slope and intercept when $\log \left(q_{\mathrm{e}}-\mathrm{q}_{\mathrm{t}}\right)$ was plotted against $t$ was used to determine the rate constant $\left(k_{1}\right)$ and $q_{\mathrm{e}}$ respectively. As shown in Figure 5 , the correlation coefficients of both USCB and TSCB were lower than 0.9 , indicating that adsorption data did not fit into the pseudo first order model. Data were fitted into the second-order model and a linear plot with high correlation co-efficient $(>0.9)$ was determined (Figure 6). This suggests that the pseudo second-order is better applicable to explain the adsorption process.

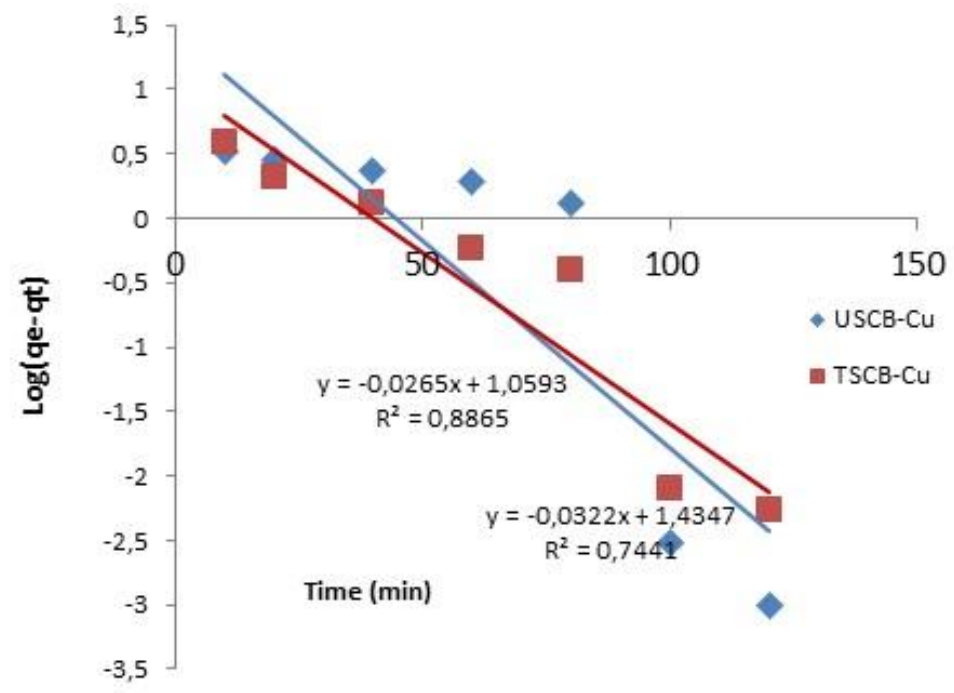

Figure 5. Lagergren pseudo-first-order model for adsorption of $\mathrm{Cu}$ (II) ions onto USCB and TSCB 
The intra-particle model was used to analyze experimental data and good fit plots were obtained. However, adsorption of USCB $\left(R^{2}=0.932\right)$ fitted better than TSCB $\left(R^{2}=0.885\right)$. Also, low $k_{w}$ less than one for both USCB and TSCB describes low bonding and slow rate of adsorption rate between adsorbent and sorbate (Erhan et al., 2004). It was also observed that the $k_{\mathrm{w}}$ of Cu II adsorption on TSCB is higher than that of USCB and this could be as a result of treatment with oxalic acid which increased the surface area for interaction.

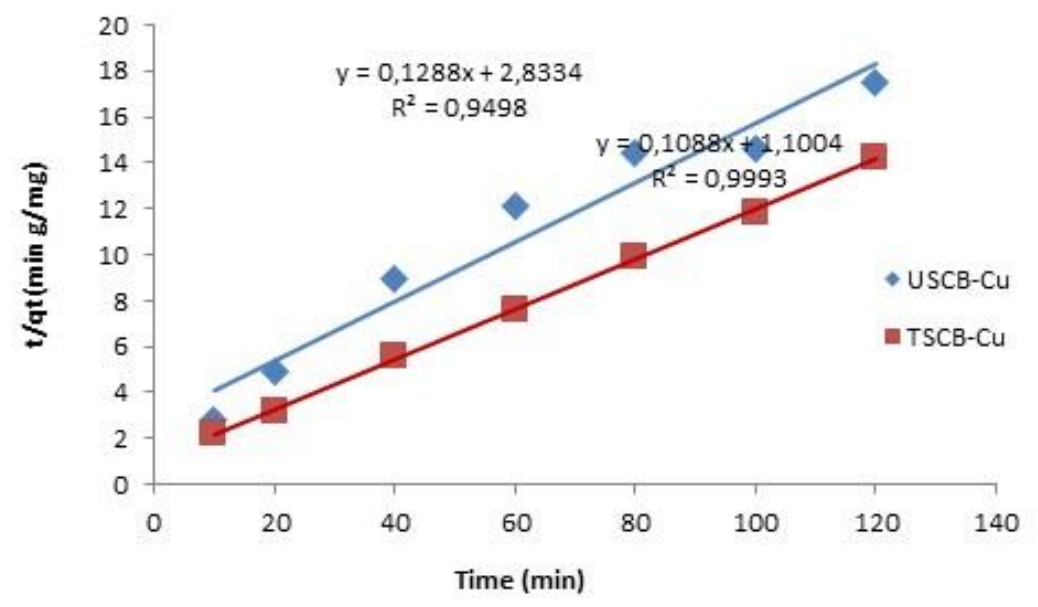

Figure 6. Ho's pseudo-second-order model for adsorption of Cu (II) ions onto USCB and TSCB.

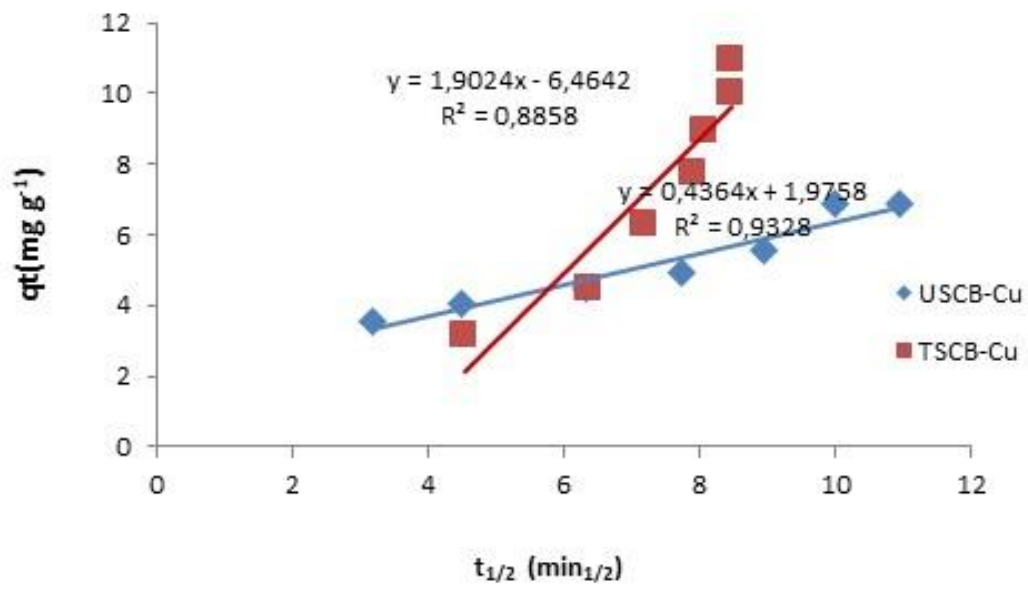

Figure 7. Intra particle model for the adsorption of CU (II) ions onto USCB and TSCB.

Table 3. The kinetic studies parameters for the adsorption of $\mathrm{Cd}$ (II) ions onto untreated and treated sugar cane bagasse.

\begin{tabular}{c|cc|ccc|ccc}
\hline Adsorbents & \multicolumn{2}{|c|}{$\begin{array}{c}\text { Intra particle } \\
\text { model }\end{array}$} & \multicolumn{3}{c|}{$\begin{array}{c}\text { Lagergrenpseudo-first- } \\
\text { order model }\end{array}$} & \multicolumn{3}{c}{ Ho's pseudo-secondorder model } \\
& $\mathrm{K}_{\mathrm{w}}$ & $\mathrm{R}^{2}$ & $\mathrm{k}_{1}$ & $q_{\mathrm{e}}$ & $\mathrm{R}^{2}$ & $\mathrm{k}_{2}$ & $q_{\mathrm{e}}$ & $\mathrm{R}^{2}$ \\
USCB & 0.673 & 0.885 & 0.074 & 27.164 & 0.744 & 0.045 & 7.813 & 0.949 \\
TSCB & 0.926 & 0.932 & 0.060 & 11.455 & 0.886 & 0.098 & 9.260 & 0.999 \\
\hline
\end{tabular}




\section{Conclusion}

Adsorption capacity is dependent on the $\mathrm{pH}$ of the solution, contact time, initial concentration of $\mathrm{Cu}$ (II) ions and temperature of the solution. The maximum amount of the $\mathrm{Cu}$ (II) ions removed from solution by USCB and TSCB at optimum $\mathrm{pH}=2$ and contact time of 100 minutes. The adsorption capacity of TSCB is more than that of USCB due to more porous surface area in the TSCB. Thermodynamic studies of the adsorption of $\mathrm{Cu}$ (II) ions unto USCB and TSCB show that the process is endothermic in nature that improved with increased temperature. Sorption data also fitted better into the second-order model while data also had good-fit when analyzed with both Langmuir and Freundlich models, but intra-particle diffusion model described a porous adsorbent with low sorption affinity.

\section{References}

Ahamed A.J. and Begum S. (2012), Adsorption of copper from aqueous solution using low-cost adsorbent, Archives of Applied Science Research, 4(3), 1532-1539.

Ali I., Asim M. and Khan T.A. (2012), Low cost adsorbents for the removal of organic pollutants from wastewater, Journal of Environmental Management, 113, 170-183.

Archana A., Sahu K.K. and Pandey B.D (2004), A comparative adsorption study of Copper on various industrial solid wastes, Wiley interscience, 50(10), 2430-2438.

Bhattia M.S., Reddy A.S. and Thukral A.K. (2009), Electrocoagulation removal of $\mathrm{Cr}(\mathrm{VI})$ from simulated wastewater using response surface methodology, Journal of Hazardous Materials, 172, 839-846.

Duygu O.H., Halil K., Basudeb S. and van Leeuwen J.H. (2008), Use of Rhizopus oligosporus produced from food processing wastewater as a biosorbent for $\mathrm{Cu}(\mathrm{II})$ ions removal from the aqueous solution, Bioresource Technology, 99, 4943-4948.

Elangovan R., Philip L. and Chandraraj K. (2008), Biosorption of hexavalent and trivalent chromium by palm flower (Borassusaethiopum), Chemical Engineering Journal, 141, 99-111.

Erhan D., Kobya M., Ehf S. and Ozkan T. (2004), Adsorption kinetics for $\mathrm{Cr}$ (Vi) removal from aqueous solution on activated carbon prepared from Agro wastes, Water SA, 30(4), 533-541.

EroL P. and Turkan A. (2008), Biosorption of chromium (VI) ion from aqueous solution using walnut, hazelnut and almond shell, Journal of Hazardous materials, 155, 378-384.

Gatsios E., Hahladakis J.N. and Gidarakos E. (2015), Optimization of electrocoagulation (EC) process for the purification of a real industrial wastewater from toxic metals, Journal of Environmental Management, 154, 117-127.

Heidmann I. and Calmano W. (2007), Removal of $\mathrm{Cr}(\mathrm{VI})$ from model wastewaters by electrocoagulation with $\mathrm{Fe}$ electrodes, Separation and Purification Technology, 61, 15-21.

Ho Y.S and Mckay G. (1998), Sorption of dye from aqueous solution by peat. Chemical Engineering Journal, 70, 115-124.

Kaushik N., Gor J.K, Shah P.N. and Modi K. (2007), Physiochemical parameter isotherms, Sorption Kinetics and column operations for adsorption of copper (II) from wastewater using fly ash, Journal of Scientific and Industrial Research, 66, 170-177.

Khalid N., Ahmad S., Toheed A. and Ahmed J. (2000), Potential of ricehusks for antimony removal, Applied Radiation and Isotopes, 52, 31-38.

Korrapati N. and Parcha S.R. (2009), Studies on removal of toxic metals from wastewater using pseudomonas species, ARPN Journal of Engineering and Applied Sciences, 7, 58-63.

Meena A.K., Mishra G.K., Rai P.K., Rajagopal C. and Nagar P.N. (2005), Removal of heavy metal ions from aqueous solutions using carbon aerogel as an adsorbent, Journal of Hazardous materials, 122B, 161-170.

Najua D.T., Luqman C.A., Zawani Z. and Suraya A.R. (2008), Adsorption of copper from aqueous solution by Elaisguineensis Kernel activated carbon, Journal of Engineering Science and Technology, 2, 180-189. 
Pankaj Pandey, Sambi S.S., Sharma S.K. and Singh S. (2009), Batch adsorption studies for the removal of Cu (II) ions by zeoliteNaX from aqueous stream, Proceedings of the World Congress on Engineering and Computer science, 1, 122-127.

Shamik C. and Papita S. (2010), Pseudo-second-order kinetic model for sorption of malachite green onto sea shell: comparison of linear and non-linear methods, Biotechnology Department, National Institute of Technology.

Shukla S.R. and Roshan S.P. (2005), Adsorption of Cu (II), Ni (II) and Zn (II) on dye loaded groundnut shells and sawdust, Separation and purification technology, 43, 1-8.

Teker M. and Imamoglu M. (1999), Adsorption of copper and cadmium ions by activated carbon from rice hulls, Turkish Journal of Chemistry, 23, 185-191.

Vlachou M., Hahladakis J. and Gidarakos E. (2013), Effect of various parameters in removing $\mathrm{Cr}$ and Ni from model wastewater by using electrocoagulation, Global NEST Journal, 15(4), 494-503. 